\title{
Influence of phospholipid composition on cationic emulsions/DNA complexes: physicochemical properties, cytotoxicity, and transfection on Hep G2 cells
}

\author{
This article was published in the following Dove Press journal: \\ International Journal of Nanomedicine \\ 6 October 2011 \\ Number of times this article has been viewed
}

\author{
Michelle Fraga ${ }^{1,2}$ \\ Fernanda Bruxel' \\ Valeska Lizzi Lagranha ${ }^{2,3}$ \\ Helder Ferreira Teixeira' \\ Ursula Matte M,3 $^{2}$ \\ 'Post Graduation Program in \\ Pharmaceutical Sciences, Universidade \\ Federal do Rio Grande do Sul, \\ ${ }^{2}$ Gene Therapy Center, Experimental \\ Research Center, Hospital de Clínicas \\ de Porto Alegre, ${ }^{3}$ Post Graduation \\ Program in Genetics and Molecular \\ Biology, Universidade Federal do Rio \\ Grande do Sul, Porto Alegre, Brazil
}

Correspondence: Helder Ferreira Teixeira Faculdade de Farmácia, Universidade Federal do Rio Grande do Sul, Av lpiranga 2752, 90610-000

Porto Alegre, Brazil

Tel +555133085514

Fax +55 5I 33085437

Email helder.teixeira@ufrgs.br
Background: Cationic nanoemulsions have been recently considered as potential delivery systems for nucleic acids. This study reports the influence of phospholipids on the properties of cationic nanoemulsions/DNA plasmid complexes.

Methods: Nanoemulsions composed of medium-chain triglycerides, stearylamine, egg lecithin or isolated phospholipids, ie, DSPC, DOPC, DSPE, or DOPE, glycerol, and water were prepared by spontaneous emulsification. Gene transfer to Hep G2 cells was analyzed using real-time polymerase chain reaction.

Results: The procedure resulted in monodispersed nanoemulsions with a droplet size and zeta potential of approximately $250 \mathrm{~nm}$ and $+50 \mathrm{mV}$, respectively. The complexation of cationic nanoemulsions with DNA plasmid, analyzed by agarose gel retardation assay, was complete when the complex was obtained at a charge ratio of $\geq 1.0$. In these conditions, the complexes were protected from enzymatic degradation by DNase I. The cytotoxicity of the complexes in Hep G2 cells, evaluated by MTT assay, showed that an increasing number of complexes led to progressive toxicity. Higher amounts of reporter DNA were detected for the formulation obtained with the DSPC phospholipid. Complexes containing DSPC and DSPE phospholipids, which have high phase transition temperatures, were less toxic in comparison with the formulations obtained with lecithin, DOPC, and DOPE.

Conclusion: The results show the effect of the DNA/nanoemulsion complexes composition on the toxicity and transfection results.

Keywords: plasmids, cationic nanoemulsions, phospholipids, physicochemical characterization, gene transfer, stearylamine

\section{Introduction}

Gene therapy is believed by many to be the therapy of the 21 st century because it aims to eradicate the cause rather than the symptoms of disease by delivering a normal functioning copy of the mutated gene and its associated regulatory elements into the cell nucleus. ${ }^{1}$ Thus, this type of therapy has emerged as a promising strategy for a wide range of inherited and acquired diseases. ${ }^{2}$ However, it has to overcome various hurdles to achieve efficient delivery and expression of genes at physiological levels in cells within the body. The development of safe and effective methods of implanting normal genes into human cells is one of the most important technical issues in gene therapy. Due to poor cell uptake and the biological instability of nucleic acids, gene transfer is usually performed using either viral or nonviral vectors. ${ }^{3}$ 
Viral vectors have been widely used to achieve efficient gene transfer. However, issues related to safety, risk of insertional mutagenesis, and the strong immune response generated by these vectors has limited its application., ${ }^{2,45}$ Nonviral vectors have important safety advantages over viral approaches, including reduced pathogenicity and capacity for insertional mutagenesis, as well as low cost and ease of production. ${ }^{6,7}$ However, application of non viral vectors has been held back by their poor efficiency in delivery to cells and transient expression of transgenes. Therefore, new strategies are needed for the application of these nonviral vectors as nucleic acid delivery systems. ${ }^{8,9}$

Nonviral vectors can be based on cationic polymers and lipids, with lipids showing advantages over polymers, especially regarding toxicity and biodegradability of the materials used. ${ }^{10}$ Among the cationic lipid-based vectors, the ones most described in the literature are solid lipid nanoparticles, ${ }^{11}$ liposomes, ${ }^{1,12}$ and nanoemulsions. ${ }^{7}$ Liposomes are vesicles consisting of an aqueous core enclosed in one or more phospholipid layers, whereas solid lipid nanoparticles and nanoemulsions are composed of a solid or liquid lipid oil core stabilized by an emulsifying layer. Regardless of the structure formed, all of these nonviral systems generally contain a cationic lipid that forms an ionic pair (complex) with the phosphate groups of nucleic acids. ${ }^{13}$

Cationic nanoemulsions have been more recently considered as a potential system for nucleic acid delivery. ${ }^{14}$ The interest in these systems is justified by the fact that they are biocompatible and able to form complexes with DNA, protecting them from enzymatic degradation. ${ }^{7}$ Other practical advantages include ease of production and the potential for repeated administration. ${ }^{13}$ Furthermore, some authors describe that, in some cases, the in vitro and in vivo transfection efficiency of these systems is higher than that of cationic liposomes. ${ }^{7,12}$

Therefore, this study aimed to investigate the effect of different phospholipids on the physicochemical characteristics, cytotoxicity, and transfection efficiency of complexes formed between cationic nanoemulsions and a DNA plasmid in Hep G2 cells, a cell line isolated from human hepatoma.

\section{Materials and methods Preparation of nanoemulsions}

Formulations were prepared by a spontaneous emulsification procedure as previously reported by Martini et al. ${ }^{15}$ Using this procedure, components of the oil and aqueous phase were dissolved in ethanol and water, respectively. The ethanol phase was slowly added to the water phase under moderate magnetic stirring which immediately turned into a milky phase as a consequence of emulsion formation. Solvents were then removed under reduced pressure below $50^{\circ} \mathrm{C}$ until the required final volume was obtained.

The final formulations were then composed of mediumchain triglycerides (Lipoid, Ludwigshafen, Germany), $2 \mathrm{mM}$ of the cationic lipid, stearylamine (SA, Sigma, St Louis, MO), different phospholipids, glycerol as an isotonic agent (Merck, Brazil), and water. The phospholipids added were either egg lecithin containing $80 \%-85 \%$ phosphatidylcholine (PC, Lipoid) or the isolated phospholipids, 1,2-dioleoyl-sn-glycero3-phosphocholine (DOPC, Lipoid), 1,2-dioleoyl-snglycero-3-phosphoethanolamine (DOPE, Lipoid), 1,2-distearoyl-sn-glycero-3-phosphocholine (DSPC, Lipoid), or 1,2- distearoyl-sn-glycero-3- phosphoethanolamine (DSPE, Lipoid). Different batches of $10 \mathrm{~mL}$ containing the five different cationic nanoemulsions (PC/SA, DSPC/SA, DOPC/ $\mathrm{SA}, \mathrm{DSPE} / \mathrm{SA}$, and DOPE/SA) were prepared in triplicate. A control formulation (PC) obtained in the absence of the cationic lipid was also prepared. The $\mathrm{pH}$ of the formulations was adjusted to about 7.0 with $\mathrm{HCl} 0.1 \mathrm{M}$.

Plasmid DNA was isolated using MaxiPrep High Purity columns (Invitrogen, São Paulo, Brazil) according to the manufacturer's instructions.

\section{Physicochemical characterization}

The mean droplet size, polydispersity index, and zeta potential of the nanoemulsions were determined by photon correlation spectroscopy and electrophoretic mobility, respectively, at $25^{\circ} \mathrm{C}$ and at an angle of $90^{\circ}(3000 \mathrm{HS}$ Zetasizer, Malvern Instruments, Worcestershire, UK). The samples were diluted in water for size determinations or in $1 \mathrm{mM} \mathrm{NaCl}$ solution for zeta potential measurements. Morphological examination of the nanoemulsions was performed by transmission electron microscopy (JEM-1200 ExII, Jeol, Japan). Formulations were diluted 10 times to obtain an oil phase concentration of $1 \%(\mathrm{v} / \mathrm{v})$, and then mixed with one droplet of $2 \%(\mathrm{w} / \mathrm{v})$ uranyl acetate solution (Reagen, Colombo, Brazil). The samples were then adsorbed to the 200 mesh formvar-coated copper grids, left to dry, and then visualized by transmission electron microscopy. Data were obtained for the nanoemulsions without DNA plasmid and complexed with the plasmid pTracer $^{\mathrm{TM}}$-CMV2 (Invitrogen) in the $+/$ - charge ratio of 2.0 (positive charge from cationic lipid and negative charge from DNA phosphate groups).

\section{Retention assay}

Formation of complexes between nanoemulsions and DNA plasmid was verified by agarose gel electrophoresis. 
Complexes at different charge ratios $(0.1,0.5,1.0,2.0$, 3.0 ), were obtained from a combination of a fixed amount of DNA plasmid (55 ng) with increasing concentrations of nanoemulsions. Nanoemulsions and DNA plasmid were incubated for 30 minutes to facilitate complex formation and then applied to $1 \%$ agarose gel stained with ethidium bromide. DNA plasmid was used without the associated nanoemulsion (naked) as a control.

\section{Stability assay}

To determine the stability of the cationic nanoemulsions/ DNA plasmid complexes, they were submitted to a DNase I (Invitrogen) digestion assay. After formation of complexes at different charge ratios, as described above, they were incubated with $1 \mathrm{U}$ DNase I at $37^{\circ} \mathrm{C}$ for 30 minutes. Subsequently, all the samples were submitted to phenolchloroform extraction ${ }^{16}$ to recover the DNA. The samples were then subjected to agarose gel electrophoresis. The naked DNA plasmid, with and without the enzyme, was used as the control.

\section{Cytotoxicity assay}

The toxicity of the nanoemulsions and complexes was evaluated in Hep G2 human hepatoma cells. Cytotoxicity was evaluated using the 3-(4,5-dimethylthiazol-2-yl)-2,5-diphenyl tetrazolium bromide (MTT, USB Corporation, Cleveland, $\mathrm{OH}$ ) assay according to Fraga et al. ${ }^{17}$ Cells were cultivated in Dulbecco's Modified Eagle Medium containing 10\% fetal bovine serum (Gibco, Grand Island, NY) and seeded at a density of $1 \times 10^{4}$ cells/well in a 96-well plate for 48 hours before the assay. Increasing charge ratios of the complexes were incubated with Hep G2 cells for 24 hours, then the medium was removed and MTT solution $0.5 \mathrm{mg} / \mathrm{mL}$ was added. Cells were maintained under incubation for 4 hours. After that, $100 \mu \mathrm{L}$ of dimethylsulfoxide (Synth Solutions, São Paulo, Brazil) was added to dissolve the blue formazan crystals. The optical density was measured at $570 \mathrm{~nm}$ using a plate reader (Anthos, Hamburg, Germany) after adjusting the $\mathrm{pH}$ with Sorensen's glycine buffer. Cells incubated only in Dulbecco's Modified Eagle Medium were used as a control for $100 \%$ cellular viability, while $0 \%$ of cellular viability was obtained after incubation of cells with Triton $\mathrm{X}-100(2 \%, \mathrm{w} / \mathrm{v})$.

\section{Gene transfer}

Hep G2 cells were seeded at $2 \times 10^{5}$ cells/well in a 24 -well plate and grown to $70 \%-80 \%$ confluence. Gene transfer was performed by incubating the cells with cationic
nanoemulsions/DNA plasmid complexes at a charge ratio of 2.0 for 4 hours. The DNA plasmid used was pTracer ${ }^{\mathrm{TM}}$ CMV2, a plasmid which contains the reporter gene green fluorescent protein. As a positive control for transfection, DNA plasmid was associated with the commercial reagent, Lipofectamine $2000^{\circledR}$ (Invitrogen) following the manufacturer's instructions. Twenty-four hours after transfection, DNA from Hep G2 cells was extracted using an Easy DNA Kit (Invitrogen). Green fluorescent protein quantification was performed by real-time polymerase chain reaction with TaqMan ${ }^{\circledR}$ MGB probes which were FAM $^{\mathrm{TM}}$ dye-labeled (Applied Biosystems, Foster City, $\mathrm{CA}$ ). The following sequences were used: forward primer 5'-CCACATGGTCCTTCTTGAGTTTGTA-3', reverse primer 5'-GAACGGCACTGGTCAACTTG-3', and probe 5'-TCCATGCCATGTGTAATC-3'. The polymerase chain reaction was carried out according to the manufacturer's instructions, using $10 \mu \mathrm{L}$ of TaqMan Universal PCR Master Mix, No AmpErase ${ }^{\circledR}$ UNG $(2 \times), 1 \mu \mathrm{L}$ of $20 \times$ Assay Mix, and $100 \mathrm{ng}$ of DNA in a volume of $20 \mu \mathrm{L}$ (Applied Biosystems). All the reactions were performed in duplicate using the ABI Prism ${ }^{\circledR} 7500$ SDS (Applied Biosystems). Plasmid concentrations ranging from $0.001 \mathrm{ng}$ to $5 \mathrm{ng}$ were used for the standard curve.

\section{Statistical analysis}

Results are expressed as the mean \pm standard deviation of three independent experiments. Statistical analysis of the data was performed using Student's $t$-test, one-way analysis of variance with Tukey post hoc or independent-samples Kruskal-Wallis testing on PASW (v 18.0; SPSS, Chicago, IL). Differences were considered to be statistically significant at $P<0.05$.

\section{Results Physicochemical characterization}

Droplet size ranged from $230 \mathrm{~nm}$ to $280 \mathrm{~nm}$ regardless of whether PC or isolated phospholipids were used (Table 1). The cationic nanoemulsion/DNA plasmid complexes showed a mean droplet size of about $300 \mathrm{~nm}$, with a polydispersity index of approximately $0.2-0.3$.

The PC/DNA plasmid formulation showed a negative zeta potential of about $54 \mathrm{mV}$ in a module which was significantly higher than that found before complexation $(P<0.05)$. Higher zeta potentials were observed for formulations containing the isolated phospholipids (regardless of type) when compared with those stabilized by the binary mixture of lecithin and SA $(P<0.01$; Table 1$)$. 
Table I Physicochemical properties of nanoemulsions and complexes

\begin{tabular}{|c|c|c|c|c|}
\hline & \multicolumn{2}{|l|}{ Nanoemulsions } & \multicolumn{2}{|l|}{ Complexes } \\
\hline & $\begin{array}{l}\text { Mean diameter* } \\
(\mathrm{nm})\end{array}$ & $\begin{array}{l}\text { Zeta potential } \\
(\mathrm{mV})\end{array}$ & $\begin{array}{l}\text { Mean diameter* } \\
(\mathrm{nm})\end{array}$ & $\begin{array}{l}\text { Zeta potentia } \\
(\mathrm{mV})\end{array}$ \\
\hline PC & $231 \pm 22$ & $-36.8 \pm 3.4^{\dagger}$ & $334 \pm 15$ & $-54.0 \pm \mathrm{I} .4$ \\
\hline $\mathrm{PC} / \mathrm{SA}$ & $265 \pm 14$ & $+53.3 \pm 4.8^{\ddagger}$ & $298 \pm 3$ & $+52.1 \pm 1.6$ \\
\hline DSPC/SA & $274 \pm 27$ & $+67.5 \pm 2.3^{\dagger}$ & $294 \pm 13$ & $+52.2 \pm 3.0$ \\
\hline DOPC/SA & $272 \pm 9$ & $+67.0 \pm 2.0$ & $300 \pm 17$ & $+61.3 \pm 4.5$ \\
\hline DSPE/SA & $270 \pm 14$ & $+67.3 \pm 6.4$ & $306 \pm 23$ & $+55.5 \pm 3.5$ \\
\hline DOPE/SA & $279 \pm 20$ & $+67.5 \pm 3.5^{\dagger}$ & $314 \pm 8$ & $+57.7 \pm 3.8$ \\
\hline
\end{tabular}

Notes: *Results represent the mean \pm standard deviation of three experiments; ${ }^{+}$Difference between $\zeta$-potential measurements before and after complexation with pDNA

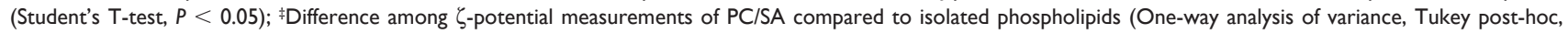
$P<0.01)$.

Abbreviations: PC, phosphatidylcholine; SA, stearylamine; DOPC, I,2-dioleoyl-sn-glycero-3-phosphocholine; DOPE, I,2-dioleoyl-sn-glycero-3-phosphoethanolamine; DSPC, I,2-distearoyl-sn-glycero-3-phosphocholine; DSPE, I,2-distearoyl-sn-glycero-3-phosphoethanolamine.

Photomicrographs showed spherical oil droplets of 200-300 nm, demonstrating a defined edge and staining with uranyl acetate (Figure 1) according to photon correlation spectroscopy. No marked influence of type of phospholipid used was detected, nor of presence of the SA cationic lipid or DNA plasmid on the morphology of the structure.

\section{Retention assay}

The results of retardation of DNA plasmid migration in agarose gel electrophoresis with different charge ratios are shown in Figure 2. Figure 2A demonstrates DNA plasmid migration in the PC formulation free of the SA cationic lipid. It is observed that there is no nucleic acid complexation with the nanostructure, with the DNA plasmid being soluble in the external phase of the nanoemulsion. On the other hand, regardless of the type of phospholipid used, for all cationic nanoemulsions containing $\mathrm{SA}$, retention of the complex was observed at the application point from the charge ratio of 1.0 (Figure 2B-F).

\section{Stability assay}

The presence of characteristic bands of intact DNA plasmid was noticed after incubation with DNAse I, indicating that complexation with cationic nanoemulsions protects DNA plasmid from enzymatic digestion (Figure 3). Results were similar for the formulations obtained with the different phospholipids. The same did not occur with DNA plasmid added to the noncationic PC formulation, suggesting that there is no DNA complexation in this nanoemulsion.

\section{Cytotoxicity assay}

The cytotoxicity assay demonstrated that addition of increasing amounts of complexes and consequently of the cationic SA lipid, leads to progressive toxicity in Hep G2 cells (Figure 4). Among the complexes evaluated, those obtained from egg lecithin (PC/SA) and isolated phospholipids DOPC (DOPC/SA) and DOPE (DOPE/SA) were the most toxic, showing reduction of cell viability by up to $80 \%$ for a charge ratio of 12.0 . On the other hand, after incubation of Hep G2 cells with the DSPC/ SA and DSPE/SA complexes, cell viability was about $60 \%$ and $40 \%$, respectively, for the charge ratio of $12.0(P<0.001$, oneway analysis of variance). The control formulation composed by medium-chain triglycerides and egg lecithin (PC) showed cell viability of about $80 \%$ at any analyzed point.

\section{Gene transfer}

In the last step of this work, the green fluorescent protein gene present in pTracer-CMV2 was used as a reporter gene to evaluate transfection efficiency. Table 2 shows the results for the different formulations, as well as for the positive control Lipofectamine 2000. Among the different formulations tested, the highest efficiency was obtained for the formulation DSPC/SA, followed by DSPE/SA. However, both were lower than Lipofectamine 2000, although without statistical significance $(P>0.05)$.

\section{Discussion}

We recently reported the development of lecithin-based nanoemulsions obtained by spontaneous emulsification as delivery systems for nucleic acids. ${ }^{6,15}$ Following up on these results, in this study we investigated the effect of different isolated phospholipids on the physicochemical properties, cytotoxicity, and transfection of nanoemulsions/DNA plasmid complexes on Hep G2 cells.

Regardless of the nature of the phospholipids (egg lecithin or isolated phospholipids), the droplet size of the nanoemulsions remained in the $250-280 \mathrm{~nm}$ range, highlighting the effect of spontaneous emulsification conditions rather than composition of the formulations on this physicochemical property. This follows in line with previous literature showing that the size of colloidal carriers obtained by solvent 

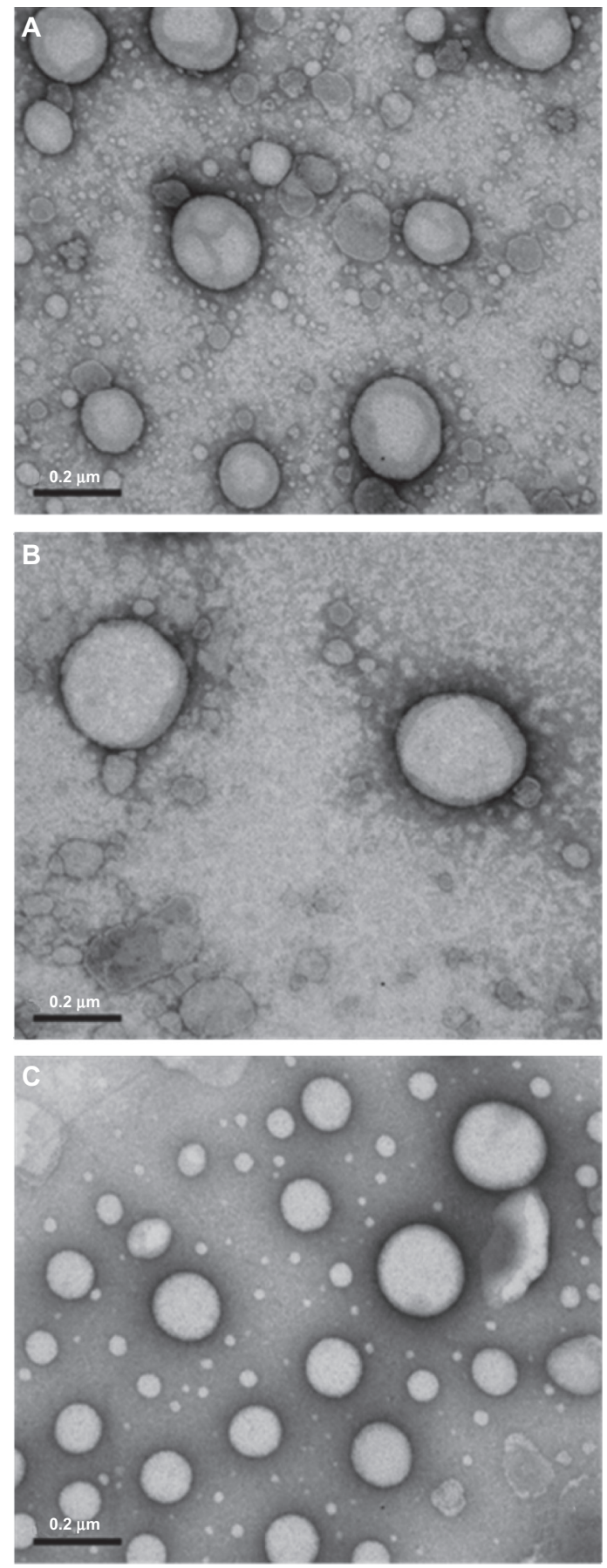

Figure I Transmission electron micrographs of the complexes formed between nanoemulsions/DNA phosphatidylcholine (A), phosphatidylcholine/stearylamine (B), and I,2-distearoyl-sn-glycero-3-phosphocholine/stearylamine (C) in the charge ratio of 2.0. 100,000× magnification.

displacement methods seems to be mainly influenced by the diffusion speed of the organic solvent in water. ${ }^{6,18}$ In the final $\mathrm{pH}$ of the formulations, the zeta potential, which was stabilized by zwitterionic PC or phosphatidylethanolamine in a binary mixture with SA, was highly positive $(>50 \mathrm{mV})$. Formulations containing isolated phospholipids showed
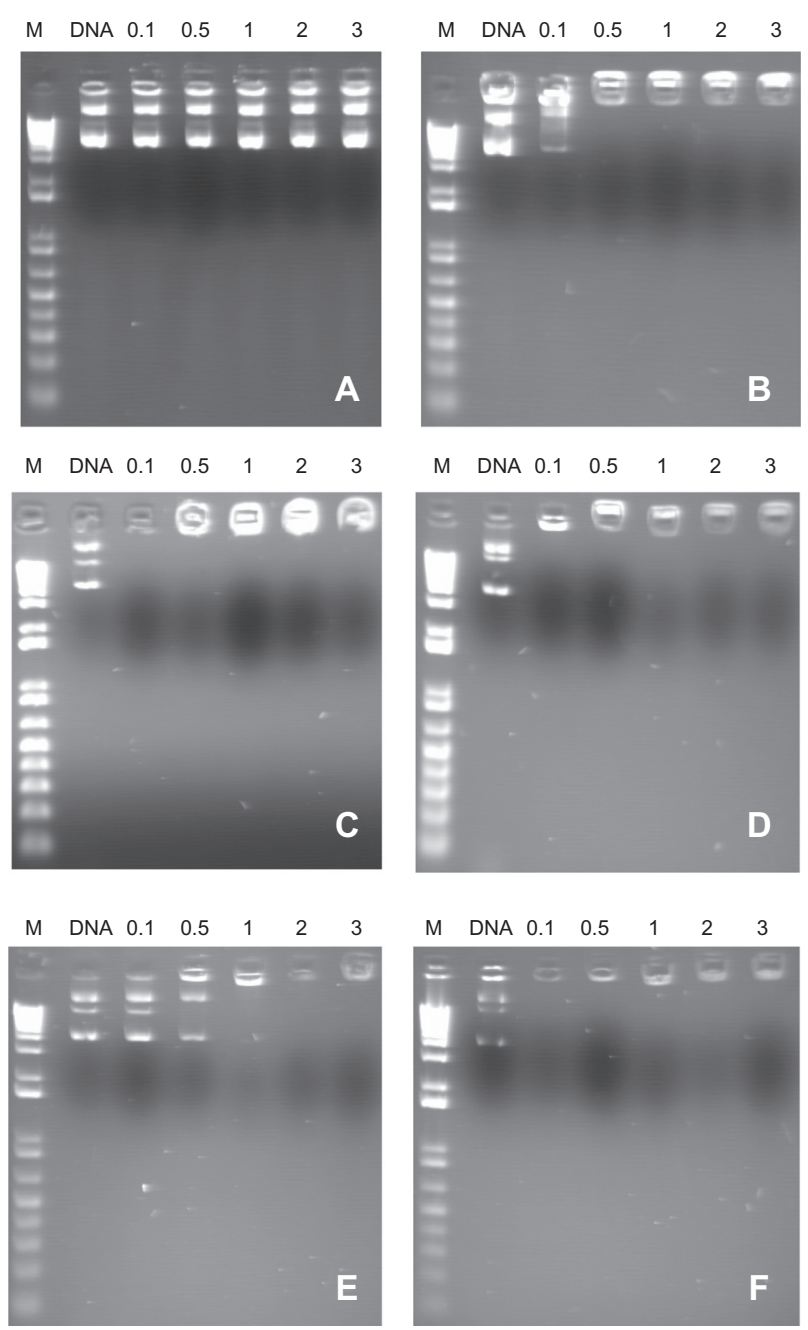

Figure 2 Migration of complexes formed between nanoemulsions/DNA plasmid phosphatidylcholine (A), phosphatidylcholine/stearylamine (B), I,2-distearoyl-snglycero-3-phosphocholine/stearylamine(C), I,2-dioleoyl-sn-glycero-3-phosphocholine/ stearylamine (D), I,2- distearoyl-sn-glycero-3- phosphoethanolamine/stearylamine (E), and I,2-dioleoyl-sn-glycero-3-phosphoethanolamine/stearylamine (F) in 1\% agarose gel. $M=$ I Kb DNA ladder; DNA plasmid = 0.I, 0.5, I.0, 2.0, and 3.0 charge ratio of cationic nanoemulsions/DNA plasmid.

significantly higher zeta potentials than that detected for the PC/SA formulation. A plausible explanation for this higher positive surface charge, at the same cationic lipid content, could be related to a partial neutralization of SA molecules by the negatively charged phospholipids from egg lecithin.

Cationic nanoemulsion/DNA plasmid complexation was evaluated using a mobility shift assay as a function of the complex charge ratio. Our results showed complete association of cationic nanoemulsions with DNA plasmid beyond a charge ratio of 1.0. DNA plasmid adsorption led to a slight increase in the droplet size of the complexes. However, no evidence of oil droplet flocculation was detected, at least for complexes obtained at a charge ratio of 2.0 , 


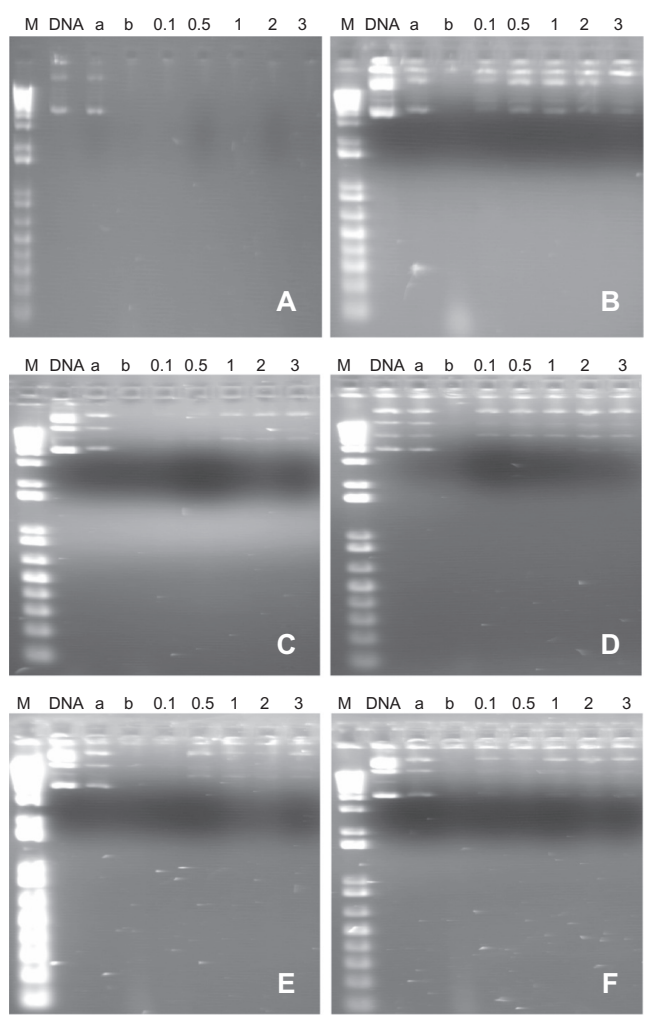

Figure 3 Migration of complexes formed between nanoemulsions/DNA plasmid phosphatidylcholine (A), phosphatidylcholine/stearylamine (B), I,2-distearoyl-snglycero-3-phosphocholine/stearylamine (C), I,2-dioleoyl-sn-glycero-3-phosphocholine/ stearylamine (D), I,2- distearoyl-sn-glycero-3- phosphoethanolamine/stearylamine (E), and 1,2-dioleoyl-sn-glycero-3-phosphoethanolamine/stearylamine (F) in I\% agarose gel, after 30 minutes of incubation with DNase I. $M=$ I Kb DNA ladder; DNA plasmid (a) = naked DNA plasmid, (b) = DNA plasmid + DNase I 0.1,0.5, I.0, 2.0, and 3.0 charge ratio of cationic nanoemulsions/DNA plasmid.

as attested by transmission electron microscopy images. Such interactions were strong enough to protect the DNA plasmid against enzymatic digestion by DNAse I over a 30-minute incubation time. DNA plasmid was retrieved in its different isoforms, ie, supercoiled, linear, and open circular. Electrostatic interactions between positively charged groups of SA and negatively charged phosphate groups of nucleic acids have been considered as the main force leading to nucleic acid adsorption and protection against enzymatic degradation. ${ }^{19-21}$

To assess the toxicity of the complexes, cell viability was determined using a MTT test in previous optimized conditions. ${ }^{17}$ In the PC/SA formulation, cell viability decreased progressively upon increasing the charge ratio, indicating the toxicity of the cationic SA lipid. Similar features were detected for complexes containing DOPE and DOPC phospholipids. Senior et $\mathrm{al}^{22}$ related the cytotoxicity of SA-based colloidal carriers to the lability of this singletailed cationic lipid at the interfaces, leading to its migration and consequent direct interaction with cell membranes. Conversely, when phospholipids exhibiting high phase-transition temperatures (DSPC and DSPE) were used instead of fluid ones (DOPC and DOPE), a significant reduction in Hep G2 toxicity could be observed, indicating the effect of these phospholipids in reducing the cytotoxicity of the complexes. Such results could be related to the more stable interface of formulations containing phospholipids bearing rigid chains when compared with their fluid counterparts, as supported by previous literature. ${ }^{23}$

The effect of phospholipid composition on nanoemulsions for Hep G2 cell transfection was evaluated by real-time polymerase chain reaction. Higher levels of green fluorescent protein were detected for complexes composed of SA and rigid phospholipids (DSPE and DSPC) at values similar to those of the positive control, Lipofectamine 2000. It has been previously postulated

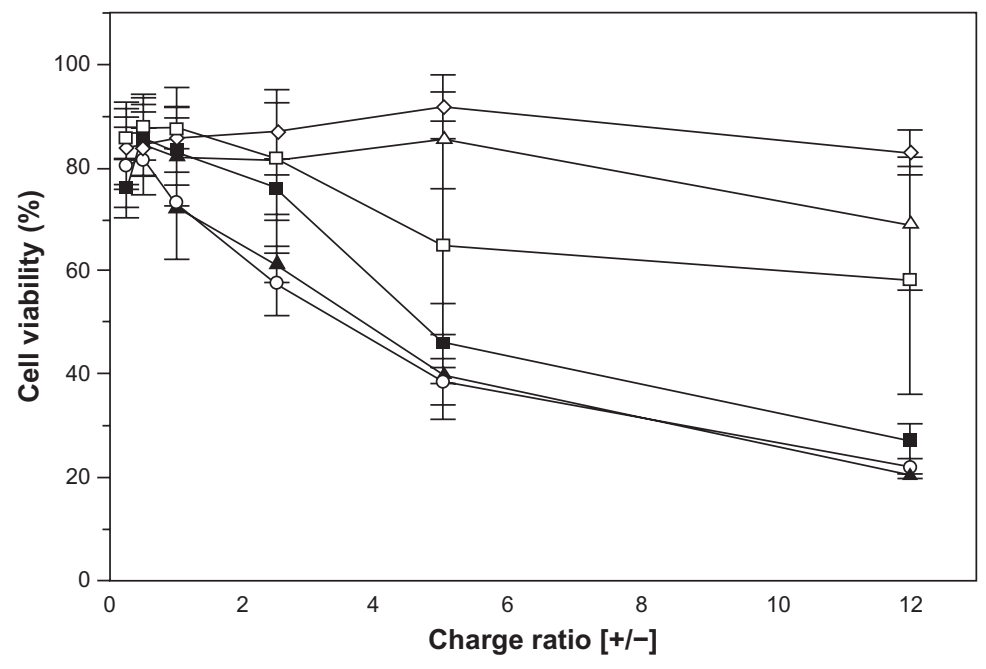

Figure 4 Viability of Hep G2 cells after incubation during 24 hours with nanoemulsions of phosphatidylcholine $(\diamond)$, phosphatidylcholine/stearylamine ( $\circ$ ), I,2-distearoylsn-glycero-3-phosphocholine/stearylamine $(\Delta)$, I,2-dioleoyl-sn-glycero-3-phosphocholine/stearylamine ( • ), I,2- distearoyl-sn-glycero-3- phosphoethanolamine/stearylamine $(\square)$ and I,2-dioleoyl-sn-glycero-3-phosphoethanolamine/stearylamine ( $\square$ ) complexed with DNA plasmid at different charge ratios. 
Table 2 Quantification of GFP DNA detected in the transfection assay of Hep G2 cells with the cationic nanoemulsions/pDNA complexes at charge ratio of $[+/-]=2.0$ by real-time PCR

\begin{tabular}{lc}
\hline Formulation & Amount of GFP DNA \\
& pg \pm SD \\
\hline PC* & $0.94 \pm 0.82$ \\
DSPC/SA & $38.0 \pm 9.4$ \\
DSPE/SA & $17.0 \pm 2.1$ \\
DOPC/SA & $5.5 \pm 0.85$ \\
DOPE/SA & $4.0 \pm 0.64$ \\
Lipofectamine $2000^{\circledR}$ & $49.9 \pm 33.6^{\dagger}$
\end{tabular}

Notes: "The complex with control formulation PC was made with equivalent amount of internal phase of the charge ratio of $[+/-]=2.0$; ${ }^{\dagger}$ Difference in amount of GFP DNA between Lipofectamine $2000^{\circledR}$ and DOPC/SA and DOPE/SA (IndependentSamples Kruskal-Wallis Test, $P<0.05$ ).

Abbreviations: GFP, green fluorescent protein; PC, phosphatidylcholine; SA stearylamine; DOPC, 1,2-dioleoyl-sn-glycero-3-phosphocholine; DOPE, 1,2-dioleoylsn-glycero-3-phosphoethanolamine; DSPC, I,2-distearoyl-sn-glycero-3-phosphocholine; DSPE, I,2-distearoyl-sn-glycero-3-phosphoethanolamine; SD, standard deviation.

that SA located at the o/w interface of nanoemulsions can induce a lysosomal escape mechanism due to its interaction with anionic lipids on the lysosomal membrane, leading to cell transfection. ${ }^{19}$ It should be mentioned that, contrary to our expectation, the DOPE-containing formulation did not improve transfection on Hep G2 cells. The literature for liposome technology has documented the positive effect of this phospholipid on transfection efficiency due to its ability to form an inverted hexagonal phase. ${ }^{1,24}$ We can speculate that a more stable interface obtained from rigid phospholipids could also lead to more stable complexes, thereby improving transfection efficiency in the case of DSPC and DSPE phospholipids. However, nanoemulsions containing DOPE need optimization of the formulation in terms of the DOPE/cationic lipid ratio and the combination of phospholipids with nonionic surfactants, as recently reported. ${ }^{24,25}$

\section{Conclusion}

This study shows the influence of phospholipid composition on the physicochemical properties of nanoemulsion. Complexation of cationic nanoemulsions with DNA plasmid occurred from the charge ratio of 1.0 for all the cationic emulsions, protecting DNA plasmid from degradation by the DNase I enzyme. Toxicity of cationic nanoemulsion/DNA plasmid complexes is mainly related to the presence of the cationic SA lipid, but a higher cytotoxicity was observed for formulations containing fluid phospholipids (DOPC, DOPE, and egg lecithin) in comparison with rigid phospholipids (DSPC and DSPE). Using a real-time polymerase chain reaction technique, it was possible to demonstrate the potential of the cationic nanoemulsions developed in this study as a gene transfer system in Hep G2 cells, with the higher transfection efficiency being detected for the DSPC/ SA formulation.

\section{Acknowledgments}

The authors wish to thank Conselho Nacional de Desenvolvimento Científico e Tecnológico (CNPq), Fundação de Amparo à Pesquisa do Estado do Rio Grande do Sul (FAPERGS), Fundo de Incentivo à Pesquisa e Eventos (FIPE) do Hospital de Clínicas de Porto Alegre (HCPA), and Coordenação de Aperfeiçoamento de Pessoal de Nível Superior (CAPES) for their financial support and Lipoid $\mathrm{GmbH}$ for providing materials for use in this work. The authors also thank Dr Mônica Cristina de Oliveira for particle size and zeta potential measurements.

\section{Disclosure}

The authors report no conflicts of interest in this work.

\section{References}

1. Karmali PP, Chaudhuri A. Cationic liposomes as non-viral carriers of gene medicines: Resolved issues, open questions, and future promises. Med Res Rev. 2007;27(5):696-622.

2. Cotrim AP, Baum BJ. Gene therapy: Some history, applications, problems, and prospects. Toxicol Pathol. 2008;36(1):97-103.

3. Nathwani AC, Benjamin R, Nienhuis AW, Davidoff AM. Current status and prospects for gene therapy. Vox Sang. 2004;87(2):7-81.

4. Barcia C, Gerdes C, Xiong WD, et al. Immunological thresholds in neurological gene therapy: Highly efficient elimination of transduced cells might be related to the specific formation of immunological synapses between T cells and virus-infected brain cells. Neuron Glia Biol. 2006;2(4):309-322.

5. Deichmann A, Hacein-Bey-Abina S, Schmidt M, et al. Vector integration is nonrandom and clustered and influences the fate of lymphopoiesis in SCID-X1 gene therapy. J Clin Invest. 2007;117(8): 2225-2232.

6. Fraga M, Laux M, Zandoná B, et al. Optimization of stearylamine-based nanoemulsions obtained by spontaneous emulsification process as nucleic acids delivery systems. J Drug Del Sci Tech. 2008;18:398-403.

7. Nam HY, Park JH, Kim K, Kwon IC, Jeong SY. Lipid-based emulsion system as non-viral gene carriers. Arch Pharm Res. 2009;32(5): 639-646.

8. Resina S, Prevot P, Thierry AR. Physico-chemical characteristics of lipoplexes influence cell uptake mechanisms and transfection efficacy. PLoS One. 2009;4(6):e6058.

9. Wasungu L, Hoekstra D. Cationic lipids, lipoplexes and intracellular delivery of genes. J Control Release. 2006;116(2):255-264.

10. Morille M, Passirani C, Vonarbourg A, Clavreul A, Benoit JP. Progress in developing cationic vectors for non-viral systemic gene therapy against cancer. Biomaterials. 2008;29(24-25):3477-3496.

11. Pedersen N, Hansen S, Heydenreich AV, Kristensen HG, Poulsen HS. Solid lipid nanoparticles can effectively bind DNA, streptavidin and biotinylated ligands. Eur J Pharm Biopharm. 2006;62(2):155-162.

12. Tu Y, Kim JS. Selective gene transfer to hepatocellular carcinoma using homing peptide-grafted cationic liposomes. J Microbiol Biotechnol. 2010;20(4):821-827.

13. Al-Dosari MS, Gao X. Nonviral gene delivery: Principle, limitations, and recent progress. AAPS J. 2009;11(4):671-681.

14. Verissimo LM, Lima LF, Egito LC, de Oliveira AG, do Egito ES. Pharmaceutical emulsions: A new approach for gene therapy. J Drug Target. 2010;18(5):333-342. 
15. Martini E, Fattal E, de Oliveira MC, Teixeira H. Effect of cationic lipid composition on properties of oligonucleotide/emulsion complexes: Physico-chemical and release studies. Int J Pharm. 2008;352(1-2):280-286.

16. Sambrook J, Fritsch EF, Maniatis T. Molecular Cloning: A Laboaratory Manual. 2nd ed. New York: Cold Spring Harbor Laboratory Press; 1989.

17. Fraga M, Laux M, Dos Santos GR, et al. Evaluation of the toxicity of oligonucleotide/cationic nanoemulsion complexes on Hep G2 cells through MTT assay. Pharmazie. 2008;63(9):667-670.

18. Mosqueira VC, Legrand P, Pinto-Alphandary H, Puisieux F, Barratt G. Poly(D,L-lactide) nanocapsules prepared by a solvent displacement process: Influence of the composition on physicochemical and structural properties. J Pharm Sci. 2000;89(5):614-626.

19. Bivas-Benita M, Oudshoorn M, Romeijn S, et al. Cationic submicron emulsions for pulmonary DNA immunization. J Control Release. 2004;100(1):145-155.

20. Hagigit T, Nassar T, Behar-Cohen F, Lambert G, Benita S. The influence of cationic lipid type on in-vitro release kinetic profiles of antisense oligonucleotide from cationic nanoemulsions. Eur J Pharm Biopharm. 2008;70(1):248-259.
21. Teixeira H, Dubernet C, Rosilio V, et al. Factors influencing the oligonucleotides release from $\mathrm{O}-\mathrm{W}$ submicron cationic emulsions. $J$ Control Release. 2001;70(1-2):243-255.

22. Senior JH, Trimble KR, Maskiewicz R. Interaction of positively-charged liposomes with blood: Implications for their application in vivo. Biochim Biophys Acta. 1991;1070(1):173-179.

23. Delattre L, Couvreur P, Puisieux F, Philippot J-R, Schuber F, editors. [Liposomes - Technological, Biological and Pharmacological Aspects]. Paris, France: Les Éditions INSERM; 1993. French.

24. Hung CF, Hwang TL, Chang CC, Fang JY. Physicochemical characterization and gene transfection efficiency of lipid emulsions with various co-emulsifiers. Int J Pharm. 2005;289(1-2):197-208.

25. Kang HS, Jin SJ, Myung CS, Hwang SJ, Park JS. Delivery of interleukin-18 gene to lung cancer cells using cationic emulsion. J Drug Target. 2009;17(1):19-28.
International Journal of Nanomedicine

\section{Publish your work in this journal}

The International Journal of Nanomedicine is an international, peerreviewed journal focusing on the application of nanotechnology in diagnostics, therapeutics, and drug delivery systems throughout the biomedical field. This journal is indexed on PubMed Central, MedLine, CAS, SciSearch ${ }^{\circledR}$, Current Contents ${ }^{\circledR} /$ Clinical Medicine,

\section{Dovepress}

Journal Citation Reports/Science Edition, EMBase, Scopus and the Elsevier Bibliographic databases. The manuscript management system is completely online and includes a very quick and fair peer-review system, which is all easy to use. Visit http://www.dovepress.com/ testimonials.php to read real quotes from published authors. 